\title{
ASPECTOS RELEVANTES DA NOVA LEI DE FRANSHING E SUAS IMPLICAÇÕES ECONOMICAS NO BRASIL
}

\author{
Luiz Artur da Silveira Dias* ${ }^{1}$ \\ Andre Lipp Pinto Bastos Lupi*²
}

\section{RESUMO}

O setor de franquias, desde o seu nascimento, passou por grandes transformações e se tornou um dos mais importantes quando se trata de expansão econômica de negócios. Isso ocorre pela possibilidade que elas trazem de expansão das atividades. No Brasil o setor tem o seu crescimento na década de 80 e nos anos seguintes passam a ser reguladas por legislações próprias, que visam dar uma maior segurança jurídica e previsibilidade para estas relações. A regulação se faz importante uma vez que o setor apresenta números fortes, sejam na esfera econômica como social. Por sua importância acaba gerando discussões no âmbito jurídico sobre qual a melhor forma de implementar essas práticas.

PALAVRA CHAVE: Franchising, economia, mercado, trabalho, contratos.

\section{RELEVANT ASPECTS OF THE NEW FRANSHING LAW AND ITS ECONOMIC IMPLICATIONS IN BRAZIL}

\begin{abstract}
Franchising was transformed along the years and became one of the most important business models, when we look at economy's business expansion. That happens because they facilitate expansion. In Brazil, franchising grew from 1980 and a specific Act governs the franchising agreement. This regulation is important, as franchising has strong figures, economically and socially. For its relevance, many legal disputes emerge about the best way to improve those practices.
\end{abstract}

KEYWORDS: Franchising, economics, market, work, contracts

\section{1 - INTRODUÇÃO}

\footnotetext{
*Luiz Artur da Silveira Dias, Mestrando em Direito Empresarial e Cidadania -UNICURITIBA, Especialista em Direito Civil e Empresarial, Direito Público e Direito tributário, Advogado e professor, email: luizarturdias@yahoo.com.br, CEP: 82600-070.

*André Lipp Pinto basto Lupi, Pós-doutor em Direito Empresarial pela Universidade de Lisboa, Doutor em Direito pela USP, com estágio doutoral no IUHEI, Genebra. Mestre e Bacharel em Direito pela UFSC. Professor permanente do curso de Mestrado em Direito Empresarial e Cidadania do UNICURITIBA. Professor de Direito Empresarial da UFSC. Professor da Especialização em Direito Empresarial e Negócios da UNIVALI. Ex-presidente da Comissão do Qualis para periódicos na Área do Direito na CAPES (2011-2014). Presidente da Comissão de Direito Empresarial da OAB/SC. Advogado, sócio de Menezes Niebuhr Advogados Associados, email: Andre@mnadvocacia.com.br
} 
O Objetivo desta pesquisa é apresentar uma visão comparativa acerca da nova legislação que entrou em vigor no ano de 2019 acerca dos contratos de franquias bem como fazer um comparativo com a legislação anterior que foi revogada. Trazendo os pontos críticos bem como as melhorias sobre o tema. Para isso a pesquisa a ser realizada será explicativa onde se registra fatos, analisa-os, interpreta-os e identifica suas causas. Com isso se busca gerar hipóteses ou ideias por força de dedução lógica. Para a construção da abordagem empírica, a opção no estudo, tanto para a estratégia de pesquisa quanto a técnica de coleta de dados, é a pesquisa documental, que consiste no estudo de informações e dados que não sofreram tratamento analítico.

As Franchisings, também conhecidas como franquias, são ferramentas muito importantes para o sistema econômico e consequentemente acabam gerando impactos no desenvolvimento social e econômico do país, uma vez que movimenta, segundo a Associação Brasileira de Franchising, quantias expressivas, que só no ano de 2020 chegou a mais de R\$ 167,1 bilhões de reais e gerou mais de 1,2 milhões de empregos diretos. Além da relevância econômica, este sistema possibilita o aperfeiçoamento de técnicas, bem como a expansão de modelos de negócio que obtiveram êxito em seus setores, diminuindo com isso os riscos do empreendedor. O sistema se baseia em um pacote de facilidades que é fornecido pelo franqueador ao franqueado que passa a utilizar de toda a expertise adquirida pelo franqueador. Segundo a Internacional Franchise Association apud Cruz (1993, p 14), "uma franquia é um contínuo relacionamento entre franchisor e o franchisee, no qual o total dos conhecimentos do franchisor, imagem, sucesso, técnicas de manufatura e marketing são fornecidos ao franchisee mediante retribuição.” Ainda nos leciona Schneider (1991), que a franchising é nada mais do que um direito que o franqueado adquire de utilizar a marca do franqueador. Vale destacar que o sistema de franquias é algo muito maior que a simples utilização da marca, uma vez que por traz desse contrato, vem uma série de outras medidas que envolvem distribuição, organização da operação em seus mais diversos aspectos, como o desenvolvimento do marketing, fornecedores dentre outras.

Esse sistema já é utilizado no mundo a bastante tempo existindo relatos desde a idade média de algo parecido com as franquias, no entanto cabe ressaltar que esse modelo de negócio, da forma como entendemos hoje, nasce nos Estados Unidos no século XIX com a I.M. Singer \& Co que era uma fábrica de máquina de costuras que repassava aos vendedores 
independentes a sua marca para que estes pudessem comercializar a sua marca e seus produtos.

No Brasil este setor foi regularizado com a lei de franquia $\mathrm{n}^{\mathrm{o}} 8.955$ de 1994 e posteriormente foi substituída por uma nova lei $\mathrm{n}^{\mathrm{o}} 13.966$ de 2019 que trouxe algumas inovações em comparada com a lei antiga. No entanto para grande parte dos estudiosos da área essas mudanças não foram tão significativas, uma vez que esta nova legislação em muito se parece com a antiga. Trouxe sim algumas modificações importantes, trazendo para a lei entendimentos que já eram pacificados pela jurisprudência, adequação de institutos já utilizados e alguns aperfeiçoamentos no intuito de dar mais segurança e perenidade para estas espécies contratuais.

O objetivo deste artigo é realizar uma análise do sistema de Franchising no Brasil sob a égide da nova lei de franquias que entrou em vigor em março de 2020. Para isso trataremos de analisar o nascimento e expansão desse sistema no mundo e no Brasil, buscando mostrar a sua dimensão e valor dentro do sistema capitalista vigente.

\section{2 - O NASCIMENTO E DESENVOLVIMENTO DAS FRANCHISING NO MUNDO E NO BRASIL}

O modelo de Franchising, a pesar de parecer algo novo, relacionado com os novos modelos de desenvolvimento e práticas comerciais que buscam o crescimento econômico é na verdade uma prática bem antiga dentro das relações econômicas de países que desenvolveram um capitalismo mais forte. Alguns autores encontram correlações com este modelo desde o período medieval. "A palavra franchisage vem de franc, radical do francês antigo que significa transferência de um direito, outorga de um privilégio ou concessão exclusiva. $\mathrm{Na}$ época do feudalismo, uma cidade franche ou franchise, era uma cidade onde as pessoas e bens tinham livre circulação" (Espinha, 2006 p.41).

Nessa época, esse sistema baseava-se em uma concessão feita pela igreja e pelos reis para que determinadas pessoas pudessem realizar a coleta dos tributos. No entanto, com a forma de organização e complexidade que entendemos hoje, esse sistema nasce no século XIX nos Estados Unidos pela empresa de máquinas de costura Singer Swing Machine Company que disponibilizava seus produtos à vendedores que deveriam realizar a comercialização (Cherto, 2006). Esses vendedores assim poderiam utilizar a marca, que tinha 
um grande prestígio, e em troca deveriam pagar taxas, além de prestar auxílios aos compradores.

No entanto, esta forma de negócio se desenvolve e se organiza de uma maneira mais sólida com o passar dos anos e principalmente após a segunda guerra mundial é que ocorrerá a sua maior expansão. Com isso grandes empresas passam a investir nessa estratégia de maneira mais intensa, quando então grandes grupos econômicos como General Motors, Coca Cola, McDonalds, dentre outras passam a crescer no mercado de consumo (BOAVENTURA, 2011). Após esse período estas marcas, já consolidadas em território pátrio passam por um processo de internacionalização e alçam novos mercados externos.

No Brasil este modelo de negócio nasce na década de 60 e teve o seu debut pelas escolas de idiomas CCAA e Yazigi que iniciaram o processo de expansão de suas marcas. Mais tarde, com o desenvolvimento urbano das cidades brasileiras este modelo encontrou um campo fértil para sua expansão e galgou seu crescimento junto com o avanço dos Shoppings Centers na década de 80 e se consolida em nosso mercado já nos anos seguintes.

Segue abaixo uma evolução histórica deste modelo no Brasil que encontrou um terreno prospero para o seu desenvolvimento e crescimento.

\begin{tabular}{|c|c|}
\hline \multicolumn{2}{|r|}{ Franchising no Brasil } \\
\hline 1960 & Surgimento com as escolas de idiomas Yazigi e CCA \\
\hline 1970 & $\begin{array}{l}\text { Maior organização e popularização com o desenvolvimento dos Shopping } \\
\text { Centers }\end{array}$ \\
\hline 1980 & Criação da Associação Brasileira de Franchising \\
\hline 1987 & Boom do Franchising no Brasil \\
\hline 1990 & Maior Profissionalização do setor e crescimento de franquias e serviços \\
\hline 1994 & Aprovação da lei de Franquias - nº 8.955/1994 \\
\hline 2015 & $\begin{array}{l}\text { Forte internacionalização das franquias brasileiras e otimização dos processos } \\
\text { com a utilização da internet }\end{array}$ \\
\hline 2000 & Década de crescimento contínuo do franchising no país \\
\hline
\end{tabular}

Fonte: site da $\mathrm{ABF}<\underline{\text { www.abf.com.br }}>$. acessado em 20/03/2021 
O êxito das franquias em território nacional não ficou estagnado no tempo. A década de 80 foi sem dúvida um grande divisor de águas, uma vez que neste período o setor deu um grande salto quantitativo e qualitativo, elevando este modelo de negócio a outros patamares, principalmente no que diz respeito ao seu faturamento. Vale destacar que o êxito das franquias se mostra cada vez mais expressivo também em seus números, o que levou o Brasil a se encontrar em uma posição confortável em termos globais no que diz respeito ao seu tamanho, bem como quanto a sua expansão, segundo o Word franchise Council (WFC) o Brasil ocupa a quinta posição em número de marcas ofertadas, totalizando 2.845, atrás apenas da Coréia do Sul (4.844), Índia (3.922), EUA (3.472) e Taiwan (3.395).

No entanto, o ano de 2020 não foi um ano fácil para o setor, porém, mesmo diante de todas as adversidades que a pandemida trouxe, ele se manteve em patamares aceitáveis quando comparável a outros setores econômicos.

Associação Brasileira de Franchising mostra o amadurecimento e crescimento, ano após ano, do número de unidades abertas, bem como no que diz respeito ao crescimento do faturamento, conforme constatado no gráfico abaixo.

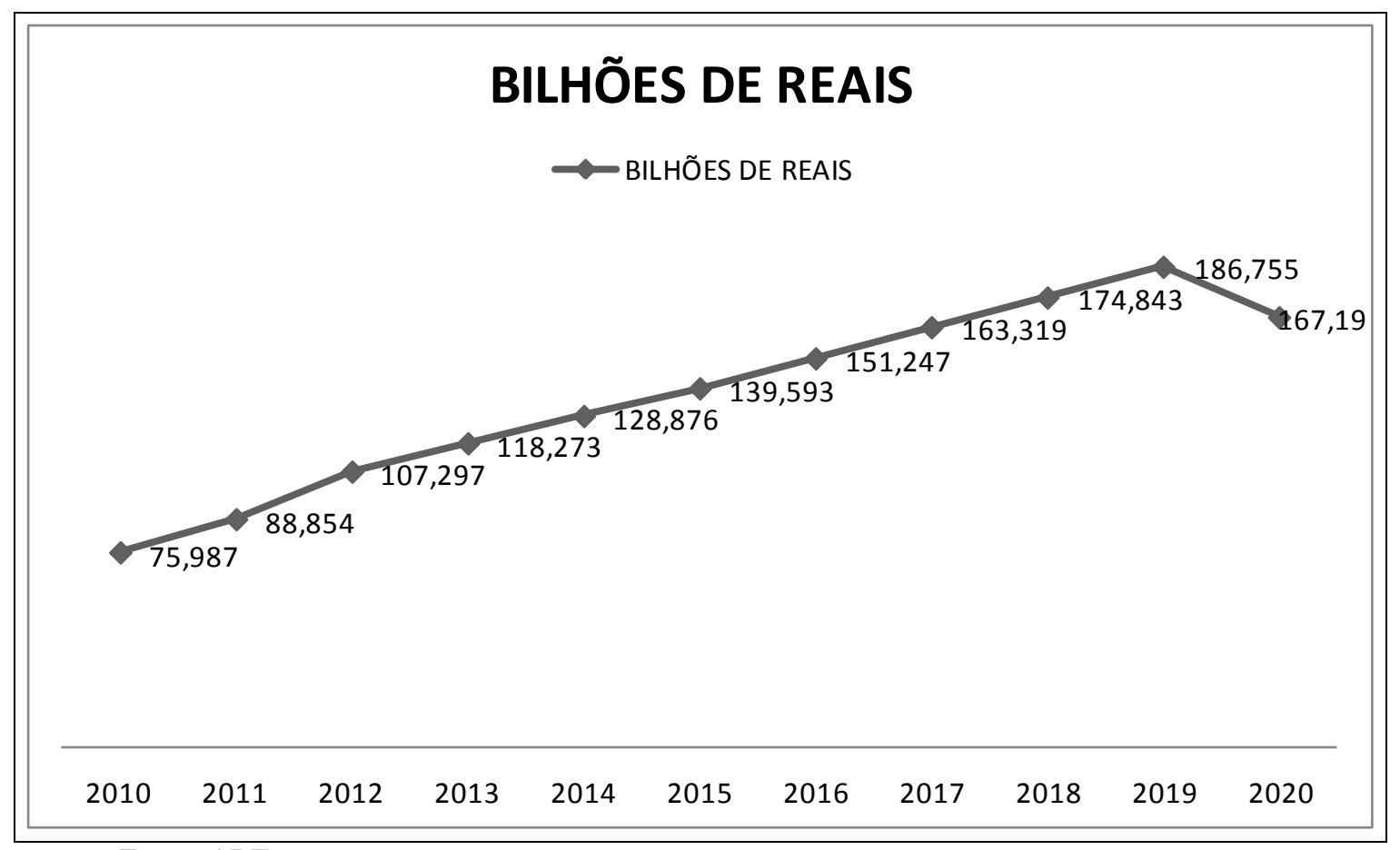

Fonte: ABF

Quando comparamos com o crescimento do Produto Interno Bruto os números são ainda mais expressivos, conforme verificamos dos dados abaixo: 


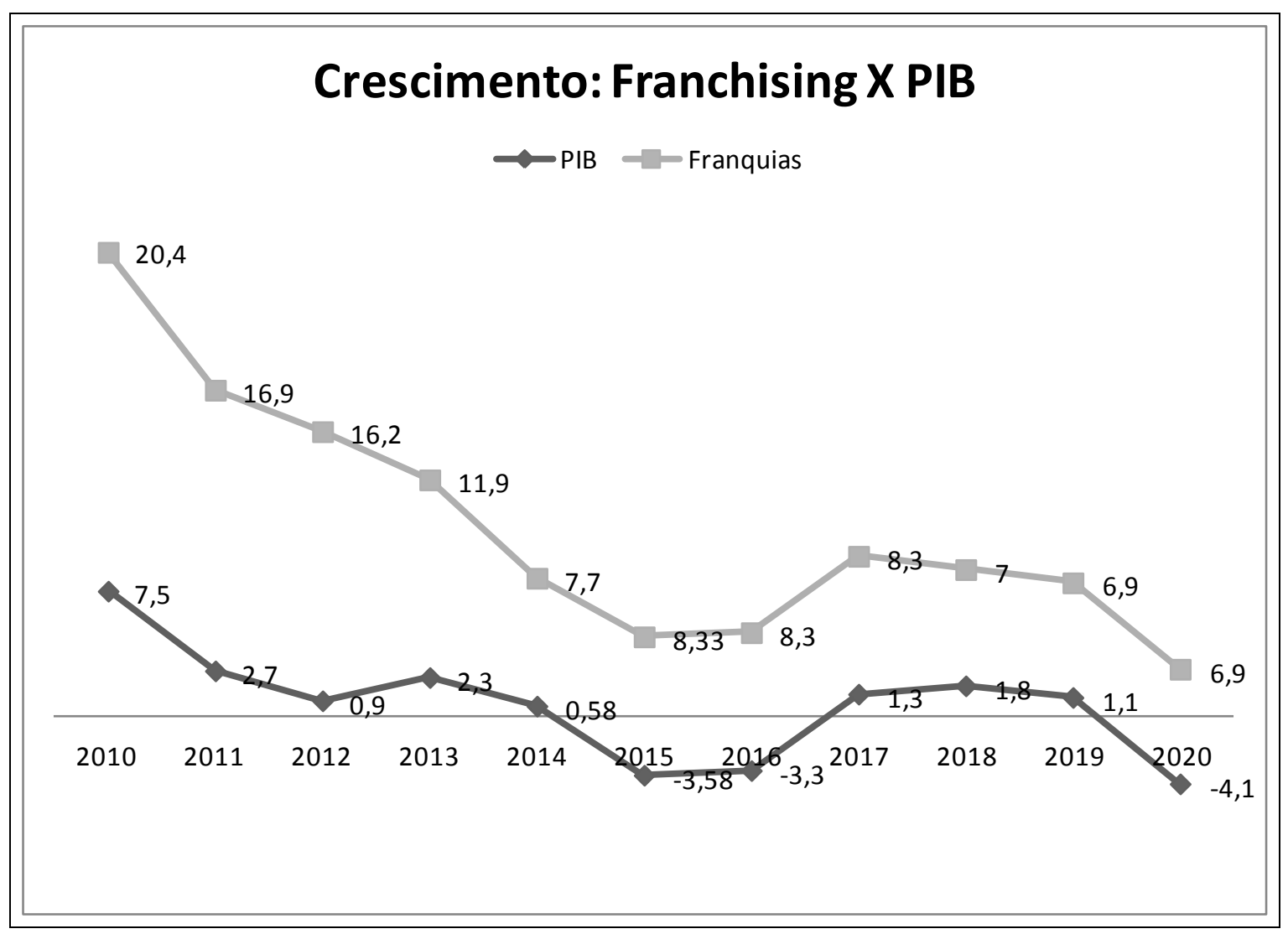

Da leitura do gráfico observamos o descolamento do crescimento do PIB com a taxa de crescimento do setor que se mostra vigorosa mesmo em cenários de crise interna, como nos anos de 2014 até 2017 onde mesmo assim o setor manteve bons resultados.

. Os dados apontam que a trajetória de crescimento sempre se manteve em patamares bastante elevados. Vale destacar que esta característica também é observada quando comparado às décadas anteriores, onde a média se manteve acima dos $10 \%$ de crescimento.

Mesmo diante desta história de sucesso, o ano de 2020, em virtude da pandemia de COVID que se alastrou pelo mundo e do qual nosso mercado não ficou de fora, trouxe preocupação no que diz respeito ao crescimento. O segundo trimestre do ano de 2020 apresentou dados de forte desaceleração, onde lojas foram fechadas e a trajetória de crescimento teve uma queda significativa com o faturamento na casa de $-35,7 \%$ quando comparado ao mesmo período do ano de 2019. Vale destacar, no entanto, que os dados também mostram uma franca recuperação já no $4^{\circ}$ trimestre do ano de 2020.

Em análise dos dados de 2020 se observa que praticamente todos os setores de franchising foram afetados com quedas importantes de faturamento, quando comparado com o mesmo período do ano de 2019, com quedas que chagaram a $88,8 \%$ como no setor de entretenimento e lazer, 68,85 no setor de moda, 45,65 no setor de alimentação, 31,15 no ramo 
da educação, dentre outros. Dos números apresentados, os setores menos atingidos foram os da Saúde, beleza e bem estar com uma queda 3,1\%, Comunicação, informática e eletrônicos com queda de $9,4 \%$ e casa e construção com uma queda de $17,7 \%$ (ABF, 2020)

No entanto, a queda não foi apenas na receita mais também na quantidade de aberturas e fechamento de lojas, quando comparado com o mesmo período de 2019, conforme se observa do gráfico abaixo.

\begin{tabular}{|l|l|}
\hline \multicolumn{2}{|c|}{ Número de Unidades } \\
\hline $\mathbf{2 0 1 6}$ & 142,593 \\
\hline $\mathbf{2 0 1 7}$ & 146,134 \\
\hline $\mathbf{2 0 1 8}$ & 153,704 \\
\hline $\mathbf{2 0 1 9}$ & 160,958 \\
\hline $\mathbf{2 0 2 0}$ & 156,798 \\
\hline
\end{tabular}

Fonte: site da ABF <https://www.abf.com.br/numeros-do-franchising/ > acessado em 10/09/2020

Apesar dos números mostrarem uma queda nas mais diversas frentes, é importante levar em consideração que o setor vive um ano atípico e que em virtude disso estes resultados negativos se fazem presentes justificando esta queda no número de unidades abertas, bem como de faturamento. Cabe destacar também que mesmo com estes dados desanimadores se espera a pronta recuperação do setor já para o ano de 2021.

\section{3 - ANÁLISE COMPARATIVA DA NOVA LEI DE FRANQUIAS BRASILEIRA}

O setor de franquias no Brasil, conforme já exposto, possui uma história vitorio e teve o seu boom na década de 80 (oitenta), o que levou a necessidade de uma melhor regulação para o setor a fim de dar um mais suporte as partes envolvidas nesse negócio, com o intuito de dar mais segurança jurídica e uma maior previsibilidade nessas relações. Foi assim que no ano de 1994 nasce a lei no 8.955/94. Com a implementação desta lei o Brasil passou por um significativo aumento no setor e áreas que antes estavam de fora desse mercado passam a se integrar ocasionando assim em uma nova fase de expansão.

A referida lei, apesar de trazer mais clareza e ser um marco para o setor, era considerada lacônica e deixava margem para discussão em assuntos relevantes para as partes envolvidas, deixando de tratar de alguns temas que mais tarde se mostraram importantes e por 
consequência acabava abrindo margem para discussões judiciais. Ela tratava de modo geral em dar mais transparecia aos contratos de franquias, criando regras e informações essenciais que deveriam estar presentes nessa relação contratual.

Apesar de importante para o setor naquele momento, a antiga legislação acabou sendo revogada pela lei 13.966/19 que objetivava trazer um maior aperfeiçoamento jurídico, uma vez que esta lei veio tipificar entendimentos doutrinários já pacificados bem como acrescentar situações que geravam interpretações dúbias acerca de determinados temas. Vale ressaltar, no entanto, que ambas as legislações não trazem grandes diferenças estruturais e sim aperfeiçoamentos e ampliações.

O conceito de franquia na nova legislação trouxe algumas diferenças quando comparada à lei anterior. Observamos isso em análise da lei 8.955/94 em seu artigo $2^{\circ}$ nos lecionava que:

Art. $2^{\circ}$. - Franquia empresarial é o sistema pelo qual um franqueador cede ao franqueado o direito de uso da marca ou patente, associado ao direito de distribuição exclusiva ou semi-exclusiva de produtos ou serviços e, eventualmente, também ao direito de uso de tecnologia de implantação e administração de negócio ou sistema operacional desenvolvidos ou detidos pelo franqueador, mediante remuneração direta ou indireta, sem que, no entanto, fique caracterizado vínculo empregatício.

. O referido artigo lecionava que o franqueador cedia ao franqueado o uso da marca ou patente. Sobre este aspecto a nova legislação trouxe uma ampliação no sentido de que o franqueado agora poderá usar marcas e outros objetos de propriedade intelectual. Com esta modificação o objeto da relação se expande uma vez que agora se relaciona com o direito autoral e com a propriedade industrial abrindo a possibilidade de utilização de licença para uso de desenho industrial, software de programas de computador dentre outras ferramentas.

Outro ponto de diferença entre as duas legislações se da quanto a distribuição, que antes era exclusiva ou semi exclusiva e que agora poderá ser também uma distribuição não exclusiva dos produtos, abrindo ao franqueado outras possibilidades de negócio.

Como dito anteriormente a lei revogada era lacônica sobre algumas questões importantes e por este motivo abria margem de discussões no judiciário que muitas vezes interpretavam a mesma questão de maneiras diferentes, trazendo com isso uma insegurança jurídica. A nova legislação além de ampliar o conceito de franquia, trazendo para o contrato a propriedade industrial, trouxe também novas questões importantes. 
A lei 13.966/19 modifica a legislação anterior como podemos observar da leitura de seu artigo $1^{\circ}$ trazendo para o debate questões como o vinculo empregatício, questão consumerista, dentre outras. Da leitura do referido artigo podemos observar estas modificações, como veremos abaixo.

\begin{abstract}
art. $1^{\circ}$ Esta Lei disciplina o sistema de franquia empresarial, pelo qual um franqueador autoriza por meio de contrato um franqueado a usar marcas e outros objetos de propriedade intelectual, sempre associados ao direito de produção ou distribuição exclusiva ou não exclusiva de produtos ou serviços e também ao direito de uso de métodos e sistemas de implantação e administração de negócio ou sistema operacional desenvolvido ou detido pelo franqueador, mediante remuneração direta ou indireta, sem caracterizar relação de consumo ou vínculo empregatício em relação ao franqueado ou a seus empregados, ainda que durante o período de treinamento
\end{abstract}

No que tange a questão consumerista a nova legislação, trouxe o entendimento que já era pacífico na jurisprudência no sentido da não aplicação da relação de consumo. Este era um grande ponto que gerava embates no judiciário, abrindo margens de decisões isoladas que geravam grande insegurança. Agora o tema esta positivado e se apresentam de maneira expressa e clara pela não existência deste vínculo, uma vez que o franqueado não é o destinatário final dos bens ou serviços contratados que serão direcionados a sua atividade econômica.

O Superior Tribunal de Justiça já havia se manifestado sobre o tema no sentido de não aplicação desta relação. Assim, a ministra Nancy Andrighi nos lecionou que "não há uma relação de consumo tutelada pelo Código de Defesa do Consumidor (CDC), mas de fomento econômico, com o intuito de estimular as atividades empresariais do franqueado".

Ainda sobre o tema o ministro Carlos Alberto Menezes em Recurso especial 687.322 destacou que "O critério fundamental, sem dúvida, para a melhor identificação da existência de relação de consumo é o da vulnerabilidade, nas suas diversas projeções, porque permite enlaçar o Código de Defesa do Consumidor com a teoria moderna dos contratos, que finca raízes mais fortes na boa-fé e na destinação social".

Posteriormente em Agravo Regimental em Recurso Especial 1.193.293 a segunda turma deste tribunal, também tratou do tema e o ministro relator do caso se posicionou pela inviabilidade da equiparação do empresário a um consumidor o que se justificaria a inaplicabilidade do Código de Defesa do Consumidor.

Essa judicialização ocorria uma vez que a lei 8.955/94 não tratava especificamente do tema, o que abria margem para essas discussões no judiciário, que conforme exposto já 
tinha entendimento pacificado sobre a matéria. Apesar deste entendimento a lei ainda suscitou discussão no que tange a caracterização ou não do contrato de franquia como um contrato de adesão. Isso possibilitaria a discussão destas cláusulas, uma vez que, havendo dúvida/ambiguidade na interpretação de um contrato de adesão ela deveria ser interpretada em favor do aderente nos termos do artigo 423 do Código Civil, que nos tipifica "Quando houver no contrato de adesão cláusulas ambíguas ou contraditórias, dever ser adotado a interpretação mais favorável ao aderente".

Nesse sentido a Ministra Nancy Andrighi nos lecionava que o contrato de franquia é inegavelmente um contrato de adesão e que por este motivo "mesmo aqueles que não consubstanciam relações de consumo, como os contratos de franquia, devem observar o disposto no artigo $4^{\circ}$, parágrafo $2^{\circ}$, da Lei 9.307/1996 (Lei de Arbitragem)". Vale destacar que o tema é controverso na doutrina, pois muitos pesquisadores do direito entendem que a decisão da ministra aborda o tema de maneira generalista tratando todos os contratos de franquia como de adesão, quando na realidade seria necessária uma análise mais detalhada do caso concreto e a observância da presença ou não dos requisitos que caracterizariam um contrato de adesão. A doutrina não afasta a hipótese de alguns contratos de franquia se assemelhar aos de adesão, porém seria necessária a observância da chamada de dependência empresarial.

Esse entendimento gerava discussões no poder judiciário que muitas vezes como, por exemplo, no tema o Recurso Especial 1.602.076 abria a possibilidade de nulidade de qualquer compromisso arbitral em sede de contrato de franquia, considerando este ilegal uma vez que considerava a vulnerabilidade do franqueado frente ao franqueador por considerar esta relação como um contrato de adesão. Para evitar este tipo de discussão a nova lei traz uma previsão expressa sobre o tema em seu artigo sétimo, parágrafo $\S 1^{\circ}$ que "As partes poderão eleger juízo arbitral para solução de controvérsias relacionadas ao contrato de franquia.”. Desta forma, a nova lei de franquias busca dirimir eventuais lacunas da lei revogada.

Outro ponto que gerava intensa discussão era no sentido da configuração de vinculo trabalhista e muito se debateu sobre a possibilidade de sua aplicação nessas espécies contratuais. A nova lei de Liberdade Econômica 13.966/19 vai sepultar este assunto já em seu artigo primeiro que nos traz a redação no sentido de não "caracterizar relação de consumo ou vínculo empregatício em relação ao franqueado ou a seus empregados, ainda que durante o período de treinamento." 
Em análise do referido dispositivo observamos a tipificação da não caracterização do vinculo consumerista, que conforme exposto já era algo pacificado, e a reinteração da não incidência do vinculo trabalhista. Vale destacar que a lei revogada já trazia esta determinação em seu artigo $2^{\circ}$. A inovação se deu com o acréscimo dos empregados que participavam de treinamentos. Esse ponto também geravam embates jurídicos sobre o vínculo entre os empregados em treinamento com os franqueadores que muitas vezes eram chamados na justiça do trabalho.

Esse ponto gerou, e acredito que continuará gerando, grandes discussões no âmbito do judiciário, pois o entendimento de parte da jurisprudência dos Tribunais Superiores Trabalhistas é no sentido de sua aplicação, conforme julgado transcrito abaixo.

TRT-3 - RECURSO ORDINARIO TRABALHISTA RO 00100458320195030165 0010045-83.2019.5.03.0165 (TRT-3)

Jurisprudência $\cdot$ Data de publicação: 06/02/2020

RECONHECIMENTO

DO VÍNCULO EMPREGATÍCIO COM

A FRANQUEADORA. Um contrato de franquia, regularmente firmado, em princípio, não gera vínculo empregatício entre a empresa franqueadora e o proprietário da franqueada, porque o objeto desse contrato é a cessão, a esta por aquela, do direito de uso da marca ou patente, associado ao direito de distribuição exclusiva ou semi-exclusiva de produtos ou serviços e, eventualmente, também ao direito de uso de tecnologia de implantação e de negócio ou sistema operacional, consoante art. $2^{\circ}$ da Lei 8.955 /94. No entanto, esse conceito legal não impede que um contrato formalizado sob roupagem de franquia seja, material e efetivamente executado, como um contrato de trabalho. Não raro ocorre de se verificar a clara tentativa de algumas empresas de, no intuito de encobrir o verdadeiro contrato de trabalho, forjar contratos de terceirização, de cooperação ou de franquia em evidente fraude à legislação trabalhista, como ocorreu na hipótese dos autos, em que a relação era pessoal, continuada e subordinada, com o trabalho prestado nas dependências da franqueadora, que pagava uma bolsa e comissões pelas vendas de seguro de vida efetuadas pelo trabalhador.

A tese para a aplicação do vinculo trabalhista é que a CLT é uma norma de ordem pública que estabelece em seu artigo $9^{\circ}$ a seguinte redação "Serão nulos de pleno direito os atos praticados com o objetivo de desvirtuar, impedir ou fraudar a aplicação dos preceitos contidos na presente Consolidação". Visto isso, ficaria a encardo do judiciário verificar se os requisitos do vínculo de emprego estão ou não presentes para configurar a relaçãoempregatícia. Vale destacar que já é entendimento pacificado, dos tribunais trabalhistas, bem como do próprio Tribunal Superior do Trabalho, no sentido da não aplicação do vínculo trabalhista para os contratos de franquias que os critérios legais forem regulamente observados, ou seja, a não ocorrência de fraude ou desvirtuamento dos contratos empresarias. 
Este é um tema importante, pois o setor emprega mais de 1,2 milhões de pessoas de forma direta e será necessário acompanhar o entendimento da jurisprudência sob a égide da nova lei.

Relevante também destacar a necessidade que a nova lei traz em seu artigo $1^{\circ}$ parágrafo primeiro, no que tange a obrigatoriedade do franqueador comprovar ao franqueado de que é o titular ou querente de direitos sobre a marca e outros objetos de propriedade intelectual negociados no âmbito do contrato de franquia ou pelo menos esteja expressamente autorizado pelo titular. Essa dúvida era recorrente por parte dos franqueados no sentido da possibilidade do franqueador, com apenas o depósito no Instituto Nacional da Propriedade Industrial (INPI) poder estabelecer contratos de franquia se utilizando desta marca. Aqui, mais uma vez a nova lei veio consolidar o entendimento já pacificado nos tribunais. Quando insere no texto legal a palavra querente quer dizer que ele fez a solicitação junto ao órgão competente, porém o processo de solicitação ainda não foi finalizado. O texto legal dexa claro esta possibilidade e com isso uma maior segurança e estabilidade para essa questão. A lei anterior tratava que só o titular de uma marca ou de uma patente poderia fazer o sistema de franquia, agora o requerente também pode. Ficando ao interessado, ou seja, ao franqueado, fazer a sua análise de risco quanto ao possível indeferimento do pedido do franqueador.

Outro ponto inovador é que o novo texto, em seu parágrafo $2^{\circ}$ trouxe a possibilidade de empresas estatais ou até mesmo entidades sem fins lucrativos poderem adotar o sistema de franquias o que antes só era possível por empresas privadas, com isso mais uma vez observamos uma extensão do conceito de franquias trazendo assim mais atores e mais estabilidade nas relações acerca dos contratos empresariais.

$\mathrm{O}$ artigo $3^{\circ}$ do novo diploma legal trata da legitimidade que agora o franqueador tem de propor ação renovatória do contrato de sublocação exigindo a renovação compulsória deste contrato. Antes da entrada em vigor da lei 13.966/19 esta possibilidade era restringida pela lei 8.245/91, também conhecida como lei do inquilinato. Esta legislação em seu artigo $51^{\circ}$, parágrafo primeiro nos traz a seguinte redação:

$\S 1^{\circ} \mathrm{O}$ direito assegurado neste artigo poderá ser exercido pelos cessionários ou sucessores da locação; no caso de sublocação total do imóvel, o direito a renovação somente poderá ser exercido pelo sublocatário. 
Com isso o franqueador ficava impossibilitado de propor a ação renovatória de contrato de locação, problema que agora está resolvido pela nova previsão legal conforme transcrição abaixo:

Art. $3^{\circ}$ Nos casos em que o franqueador subloque ao franqueado o ponto comercial onde se acha instalada a franquia, qualquer uma das partes terá legitimidade para propor a renovação do contrato de locação do imóvel, vedada a exclusão de qualquer uma delas do contrato de locação e de sublocação por ocasião da sua renovação ou prorrogação, salvo nos casos de inadimplência dos respectivos contratos ou do contrato de franquia.

Com isso, tanto o locatário como o sublocatário poderão ajuizar ação renovatória. Ainda sobre o artigo $3^{\circ}$ da lei 13.966/19 cabe destacar mais uma inovação importante acerca dos contratos empresariais.

A lei 8.245/91 que trata da locação de bens imóveis, nos traz a seguinte redação:

Art. 21. O aluguel da sublocação não poderá exceder o da locação; nas habitações coletivas multifamiliares, a soma dos aluguéis não poderá ser superior ao dobro do valor da locação.

Parágrafo único. O descumprimento deste artigo autoriza o sublocatário a reduzir o aluguel até os limites nele estabelecidos.

Em leitura do referido dispositivo observamos a impossibilidade do sublocatário exceder o aluguel da sublocação ao da locação original. Ocorre que a nova lei de franquia empresarial traz esta possibilidade quando em seu artigo $3^{\circ}$, inciso II estabelece que o valor pago pelo franqueado ao franqueador na sublocação poderá ser maior e isso não implicará em onerosidade excessiva.

Cabe ressaltar que estruturalmente falando não ocorreu uma grande mudança entre a lei 8.922/94 para a lei 13.966/19. Observa-se que as mudanças ocorridas trouxeram uma adequação as novas realidades, inserindo entendimentos que já eram pacíficos e a busca pelo preenchimento de lacunas com o intuito de diminuir possíveis conflitos.

\section{4 - ALTERAÇÔES RELEVANTES NA CIRCULAR DE OFERTA DE FRANQUIAS}

A Circular de Oferta de Franquias (COF) que se trata de um rol de dados que visa dar ao futuro franqueado informações essenciais sobre o franqueador, para que possa fazer u ma reflexão e analisar se o investimento é viável ou não e assim tomar a sua decisão. A lei 
permite ao futuro franqueado em casos de equívocos ou incompatibilidades nas informações constantes na COF a devolução de todos e quaisquer valores já pagos.

O prazo legal e a obrigatoriedade quanto a apresentação da COF foram mantidos na nova lei, porém agora temos a presença de uma exceção quanto aos órgãos ou entidades publicas em que a COF será divulgada logo no inicio do processo de seleção. Isso ocorre pois a nova legislação, como dito anteriormente, traz a possibilidade da administração pública participar destas relações contratuais.

Prazo legal é o prazo que o futuro franqueado tem para analisar os dados apresentados na circular de oferta de franquias. O titular oferece este documento ao candidato que por um prazo mínimo de 10 dias analisará as informações apresentadas. As situações em que este prazo não seja respeitado era tratado pela antiga legislação em seu artigo $4^{\circ}$, parágrafo único com possibilidade que tinha o franqueado de arguir a anulabilidade do contrato e exigir devolução de todas as quantias que já havia pago a franqueador ou terceiros. Com o advento da nova lei criou-se a possibilidade do franqueado arguir também a nulidade deste contrato, porem retirou a possibilidade das perdas e danos.

Trouxe também à nova lei algo inovador que agora é item obrigatório na COF que é a presença de um histórico resumido do franqueador, com a apresentação de sua evolução no negocio, a sua recepção no mercado empresarial dentre outras informações relevantes. A legislação em seu artigo $2^{\circ}$, inciso $\mathrm{X}$, também ampliou o prazo da relação de franqueados, subfranqueados ou subfranqueadores que antes era de doze meses e agora passa a ser de 24 meses, ou seja o franqueador deverá oferecer a informação completa, com o nome, endereço, telefones, para que o candidato possa fazer uma pesquisa mais apurada de informações que ele ache importante para a efetivação do contrato.

O artigo $2^{\circ}$, inciso XVII também trouxe outra inovações importante com a necessidade de indicação das situações em que poderão ser aplicadas as penalidades bem como as multas ou indenizações em razão de descumprimento das regras contratuais.

Outra alteração importante, no que tange ao estabelecimento de informações sobre as cotas mínimas de compra do franqueado frente ao franqueador, veio resolver um problema recorrente nestas relações. O inciso XIX do artigo $2^{\circ}$ na nova lei exige que estas informações sejam mais claras e determinadas, possibilitando ao franqueado inclusive a recusa da compra. Vale ressaltar que a jurisprudência já acompanhava este entendimento.

A questão da abrangência territorial também era um tema sensível neste tipo de contrato, pois na COF deveria constar, pela legislação revogada, as informações relativas a 
atuação territorial apenas entre franqueados. O novo texto trouxe também para a discussão a concorrência entre Franqueados e Franqueador, como se observa da transcrição do inciso XI, artigo segundo da lei abaixo:

XI - informações relativas à política de atuação territorial, devendo ser especificado: a) se é garantida ao franqueado a exclusividade ou a preferência sobre determinado território de atuação e, neste caso, sob que condições;

b) se há possibilidade de o franqueado realizar vendas ou prestar serviços fora de seu território ou realizar exportações;

c) se há e quais são as regras de concorrência territorial entre unidades próprias e franqueadas;

Com isso, podemos verificar que a concorrência entre os franqueados e as unidades próprias dos franqueadores passa a ser objeto de discussão na própria $\mathrm{COF}$ criando um ambiente com melhor transparêcia.

Ainda sobre a Circular de Oferta de Franquia, a legislação antiga em seu artigo $7^{\circ}$ aplicava a penalidade de anulabilidade do contrato nas situações em que o franqueado apresentasse informações falsas na COF. Conforme se verifica abaixo:

Art. $7^{\circ}$. - A sanção prevista no parágrafo único do art. $4^{\circ}$. desta Lei aplica-se, também, ao franqueador que veicular informações falsas na sua Circular de Oferta da Franquia, sem prejuízo das sanções penais cabíveis.

O novo texto inseriu em seu artigo $4^{\circ}$ a possibilidade de anulabilidade ou até mesmo nulidade do contrato quando a COF não só apresentar informações falsas como também omitir informações importantes.

Sobre o tema vale destacar o entendimento de alguns autores no que tange a essas modificações trazidas pelo novo ordenamento.

\section{"modificação de conteúdo substancial:}

A relação de ex-franqueados desligados da rede deverá contemplar todos os ex-franqueados que se desligaram nos últimos 24 (vinte e quatro) meses, ao invés dos últimos 12 (doze) meses conforme previsto na Lei anterior;

As informações relativas à política territorial deverão contemplar, também, informações acerca das regras de concorrência territorial entre unidades próprias e franqueadas;

As informações acerca do que é oferecido pelo franqueador ao franqueado deverão contemplar, também, informações sobre a incorporação de inovações tecnológicas às franquias, bem como leiaute e padrões arquitetônicos das instalações do franqueado, incluindo arranjo físico de equipamentos e instrumentos, memorial descritivo, composição e croqui; 
As informações relativas à marca do franqueador deverão ser prestadas de forma mais completa, incluindo outros direitos de propriedade intelectual relacionados à franquia, cujo uso será autorizado em contrato pelo franqueador, bem como a caracterização completa, com o número do registro ou do pedido protocolizado, com a classe e subclasse, nos órgãos competentes, e, no caso de cultivares, informações sobre a situação perante o Serviço Nacional de Proteção de Cultivares (SNPC);

A indicação acerca da situação do franqueado após a expiração do contrato de franquia em relação ao know-how trouxe conceitos mais detalhados relativos a know-how e segredos de negócio" Frustockl, Dutra (2020, p. 7)

Além destas alterações a nova lei também trouxe novos itens que devem estar presentes conforme nos leciona Frustockl, Dutra (2020):

Indicação da existência - ou não - de regras de transferência ou sucessão, e quais são elas em caso positivo; Indicação das situações em que são aplicadas penalidades, multas ou indenizações e dos respectivos valores, estabelecidos no contrato de franquia; Informações sobre a existência de cotas mínimas de compra pelo franqueado junto ao franqueador, ou a terceiros por este designados, e sobre a possibilidade e condições para a recusa dos produtos ou serviços exigidos pelo franqueador; Indicação sobre a existência (ou não) de Conselho ou Associação de franqueados; Prestação de informações sobre quais são as regras de limitação de concorrência entre franqueador e franqueado, bem como regras de concorrência entre franqueados, enquanto estiver em vigor o Contrato de Franquia. Deverão constar não só o detalhamento da abrangência territorial, como também o prazo de vigência da restrição $\mathrm{e}$ das penalidades em caso de descumprimento; Indicação de quais são as condições e prazo para renovação do Contrato de Franquia. Frustockl, Dutra (2020, p. 9)

Diversas foram as modificações introduzidas pela nova legislação no âmbito da Circular de Oferta de Franquias, sempre visando oferecer o maior grau de informação possível e dando uma maior segurança para a tomada de decisão, afastando com isso possíveis discussões sobre o conteúdo da oferta.

\section{5 - INFLUÊNCIA DAS FRANCHISING NO MERCADO DE TRABALHO}

É inegável que o setor de franquias exerce uma influência grande dentro do desenvolvimento social uma vez que é responsável pela geração de um grande numero de 
postos de trabalhos o que lhe coloca em uma posição confortável quando comparado a outros setores da economia. Só no ano de 2019 gerou quase 1,4 milhões de postos de trabalhos diretos sem mencionar os empregos indiretos. (ABF, 2019)

Conforme informações as Associação Brasileira de Franchising a geração de empregos nos 11 setores pesquisados apresentaram uma taxa de crescimento muito boa quando comparado com outros setores econômicos, com destaque para os serviços educacionais que teve um crescimento de 8,7 (ABF, 2019).

Contudo, verificamos que o setor apresentou uma queda de 7,3\% na geração de empregos no ano de 2020 quando comparado com 2019, quebrando com isso um ciclo de crescimento que vinha se solidificando ano após ano. Esse resultado nos da uma fotografia dos impactos da COVID. Os números de 2020 apresentaram uma queda nessa trajetória ascendente, e esse fato se da em virtude da pandemia que atingiu a economia do país.

Dados recentes apontam que as franquias foram responsáveis, no segundo trimestre de 2020, pela geração de 1.361 .795 empregos diretos, ou seja, apenas $0,3 \%$ a mais do que no último trimestre de 2019. Isso comprova a força e importância desse setor que buscou soluções para diminuir os impactos da pandemia, como a redução das taxas cobradas, a negociação com Shopping Centers e a postergação de planos de expansão, dentre outras medidas. (ABF, 2020).

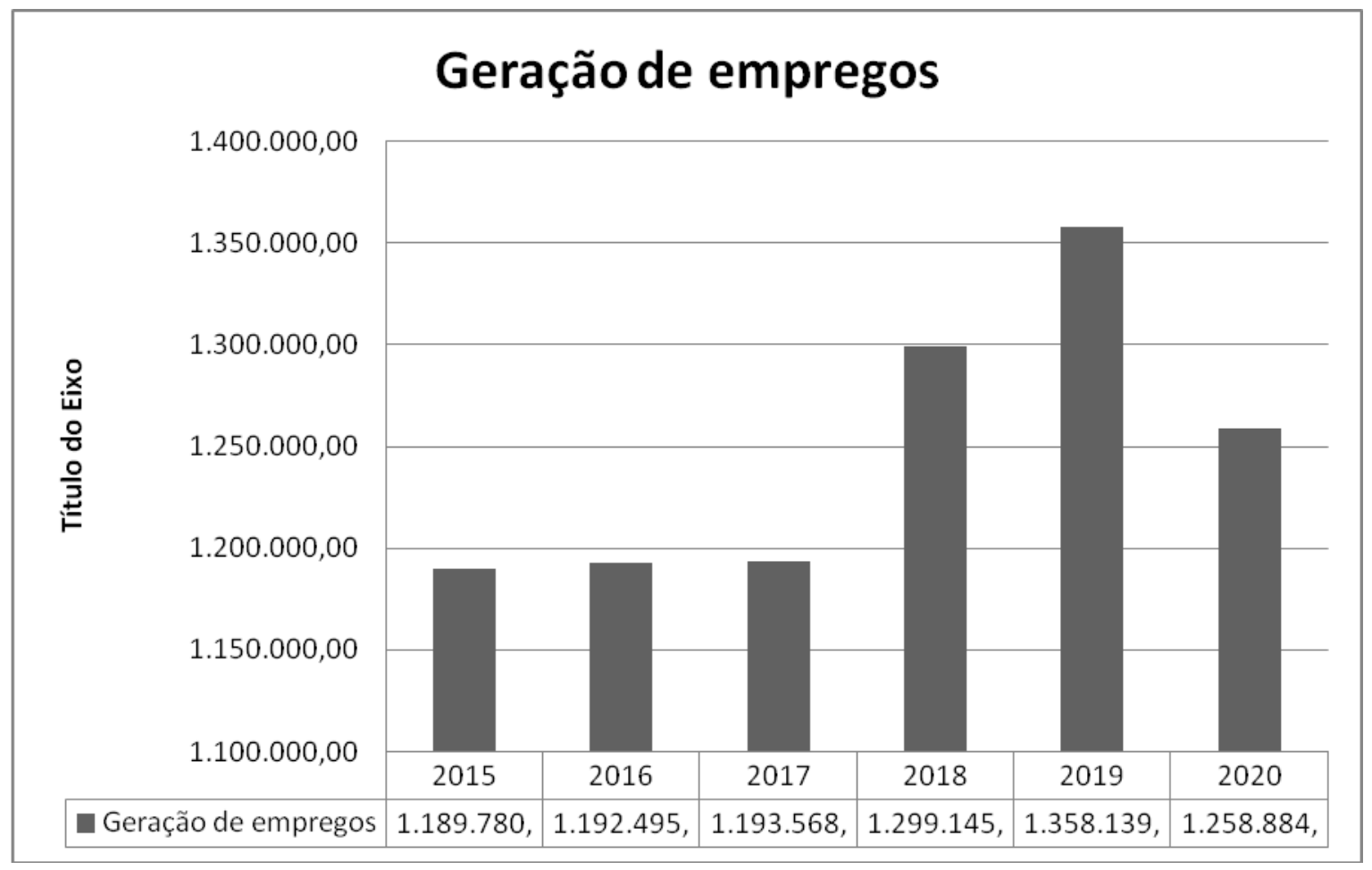


Fonte: site da ABF < https://www.abf.com.br/numeros-do-franchising/ > acessado em 10/09/2020

Certamente os números deste ano apresentarão queda na trajetória ascendente que vinha apresentando, em virtude da pandemia que atingiu a economia do país o que não afasta a sua importância como gerador de empregos. Dados recentes apontam que as franquias foram responsáveis, no segundo trimestre de 2020, pela geração de 1.361 .795 empregos diretos, ou seja, apenas 0,3\% a mais do que no último trimestre de 2019. Esses dados comprovam a força e importância desse setor que buscou soluções para diminuir os impactos da pandemia, como a redução das taxas cobradas, a negociação com Shopping Centers e a postergação de planos de expansão, dentre outras medidas. (ABF, 2020).

\section{6 - CONCLUSÃO}

O setor de franquias no Brasil e no mundo possui uma longa trajetória histórica de contribuição ao desenvolvimento de atividades econômicas, pois possibilita a expansão de setores por meio de seus franqueados diminuindo assim os riscos do negócio que passam a ser implantados por pessoas que conhecem as peculiaridades de cada mercado. Não demorou muito para o Brasil entrar nesse negócio o que levou a necessidade da criação de novos parâmetros jurídicos que visassem dar uma maior proteção aos sujeitos dessa relação.

No ano de 1994 nasce nossa primeira lei que trata do tema, oferecendo uma maior segurança e previsibilidade jurídica o que possibilitou um crescimento dessas relações e por consequência a consolidação do setor. Esta primeira lei trouxe algumas críticas, uma vez que era considerada lacônica e abria margem para discussões nos tribunais o que gerava insatisfação por parte de seus agentes. Nesse contexto buscou-se uma nova legislação que nasce no ano de 2019 e entra em vigor em março de 2020 conhecida como a lei de liberdade econômica $\mathrm{n}^{\mathrm{o}}$ 13.966/19 que veio com o intuito de aparar as arestas deixadas pelo dispositivo antigo. 
Diversas foram as modificações implementadas na nova lei, também conhecida como lei de franquias, que veio para aprimorar a legislação anterior buscando diminuir a judicialização do setor e oferecendo uma maior segurança jurídica para as partes.

.Nova lei de um modo geral mantém a estrutura da anterior e traz inovações que já eram utilizadas pelos profissionais da área, substituindo expressões ambíguas, inserindo entendimentos jurisprudenciais, criando novas exigências, sempre com a intenção de aprimorar estas relações.

Toda essa preocupação se faz necessária na busca de dar uma maior previsibilidade as partes e porque este setor apresenta uma força muito grande dentro da economia, com números expressivos em termos de faturamento e de geração de empregos o que acarretará em um forte impacto dentro do contexto social.

\section{REFERÊNCIAS BIBLIOGRÁFICAS}

BOAVENTURA, NINA. A Influencia da Rede de Franqueados na Gestão estratégica da Franqueadora: Um Estudo de Caso Múltiplo no Franchising Brasileiro. Dissertação (mestrado em Gestão Empresarial) - Fundação Getulio Vargas, Rio de Janeiro, 2011.Disponível em: https://silo.tips/download/escola-brasileira-de-administraao-publica-ede-empresas-dissertaao-apresentada-p. Acesso em: 4 set. 2020.

CHERTO ET AL. Franchising: uma estratégia para expansão de negócios - São Paulo: Premier Máxima, 2006.

CRUZ, GLÓRIA Cardoso de Almeida. Franchising. 2 ed. Rio de Janeiro: Forense,1993.

SCHNEIDER, Alexandre A. et al. Franchising da pratica para à teoria. São Paulo:

Maltese, 1991.

SIMÃO FILHO, Adalberto. Franchising: aspectos jurídicos e contratuais, comentários à Lei de Franchising, com jurisprudências. 4 ed. rev. e atual. São Paulo: Atlas, 2000.193p.

SPINHA, P.G.; MACHADO, HILKA P. V. e RODRIGUES, R. M.I. Considerações sobre o empreendedorismo e a exploração de negócios no franchising. EGEPE - Encontro de Estudos sobre Empreendedorismo e Gestão de Pequenas Empresas. 4. 2005, Curitiba, Anais... Curitiba, 2005, pp. 552-564.

FRIEDHEIM, A. Os Termos de Franchising mais utilizados por quem é desse ramo. http://www.portaldofranchising.com.br/site/content/interna/index.asp?codA=15\&codAf $=19 \&$ codC $=7$ \&origem=artigos, acessado em 15/09/2020. 
FRUSTOCKOL, Fernanda de La Rosa; DUTRA, Nathalia Carvalho. Uma análise sobre a nova Lei de Franquias e sua implementação, 2020. Disponível em: https://baptistaluz.com.br/wp-content/uploads/2020/06/Bluz_Nova-Lei-de-Franquias-e-suaimplementa\%C3\%A7\%C3\%A3o.pdf. Acesso em: 10 set. 2020.

ASSOCIAÇÂO BRASILEIRA DE FRANCHISING. Números do setor. Disponível em< https://www.abf.com.br/numeros-do-franchising/> . Acesso em: 05 de setembro de 2020 